\title{
Editorial: Forest Management Alters Forest Water Use and Drought Vulnerability
}

\author{
Christina Tague ${ }^{1 *}$, Matthew D. Hurteau ${ }^{2}$ and Anthony Parolari ${ }^{3}$ \\ ${ }^{1}$ Bren School of Environmental Science and Management, University of California, Santa Barbara, Santa Barbara, CA, \\ United States, ${ }^{2}$ Department of Biology, University of New Mexico, Albuquerque, NM, United States, ${ }^{3}$ Civil, Construction and \\ Environmental Engineering, Marquette University, Milwaukee, WI, United States
}

Keywords: species change, thinning, forest density, forest health, drought

\section{Editorial on the Research Topic}

Forest Management Alters Forest Water Use and Drought Vulnerability

\section{OPEN ACCESS}

Edited and reviewed by: Kevin J. McGuire, Virginia Tech, United States

*Correspondence: Christina Tague ctague@bren.ucsb.edu

Specialty section:

This article was submitted to Forest Hydrology,

a section of the journal Frontiers in Forests and Global

Change

Received: 23 February 2021 Accepted: 18 March 2021

Published: 13 April 2021

Citation:

Tague C, Hurteau MD and Parolari A (2021) Editorial: Forest Management Alters Forest Water Use and Drought

Vulnerability.

Front. For. Glob. Change 4:671437. doi: 10.3389/ffgc.2021.671437
Widespread, multi-year droughts are an increasing threat to forests throughout the world. Droughts are causing declines in forest productivity, increases in tree mortality, and contributing to increasing frequency and severity of disturbances including wildfire and insect outbreaks. Droughts also alter forest water use and the partitioning of limited precipitation between transpiration, evaporation, groundwater recharge, and streamflow. Ongoing climate change is likely to worsen droughts, with climate model projections indicating increasing duration and frequency in many forested regions of the globe. In the face of these threats, understanding how forests use water, particularly during droughts, and how forests respond to drought is critical for managing the services that these forests provide. Of particular relevance to forest managers is how management interventions might alter forest water use, mitigate drought vulnerability, and minimize losses of key ecosystem services. Management strategies, including changing forest structure through density reduction (thinning) and planting, which are commonly implemented to meet other objectives, have the potential to influence water demand and availability. Given the increasing drought-induced water scarcity, a key question for researchers and managers is how does management impact forest drought response?

This collection of papers provides new insights into how forest management, forest water use and droughts are interrelated. The collection considers both ecohydrologic impacts of changes in forest density (through thinning or fire) and impacts that could occur via species management.

\section{DENSITY REDUCTION AND FOREST DROUGHT RESPONSES}

Papers that examine forest density (Burke et al.; Hwang et al.; Klockhow et al., 2020; Krogh et al.; Roche et al.; Sinacore et al.; van Mantgem et al.) address a wide range of ecohydrologic processes that can change with forest density including snow accumulation and melt, evapotranspiration, streamflow, productivity/growth, fire, and mortality risk. Techniques used in these papers range from observation-based studies with sap flow (Sinacore et al.), tree rings (van Mantgem et al.), remotely sensed vegetation indices (normalized difference vegetation index, NDVI) (Hwang et al.), and eddy-covariance data (Roche) to ecosystem modeling approaches (Krogh et al.; Burke et al.; Saksa et al.).

Many of these papers suggest that density reduction alters forest drought responses, or at least increases water availability and/or productivity of the remaining trees. All of these studies however also emphasize the large range of variation in the impact of density reduction. For example, van Mantgem et al., using tree rings, and Burke et al. using a mechanistic model, both show substantial 
variation in responses to thinning intensity and climate. Burke et al. also highlights the importance of subsurface characteristics that affect plant available water storage capacity and type of thinning as controls on thinning response. Saksa et al. show substantial spatial variation with greater water yield following density reduction for the wetter central California Sierra relative to the drier Southern Sierra. Krogh et al. similarly emphasize spatial heterogeneity by showing how increases in snowmelt recharge with thinning vary spatially, even within relatively small watersheds.

Density reduction impacts are also dynamic and several of the studies note that the change in vegetation water use after density reduction recovers quickly (even within the first 5 years following density reduction) (Burke et al.; Roche et al.). While most papers explore the impacts of density reduction, Hwang et al. complements these by looking at hydrologic impacts of density increases that can occur with fire suppression. More generally, Mrad et al. provide a theoretical perspective on how forest density evolves over time, linking allometric, growth, structural and biomechanical, and metabolic mechanisms to the self-thinning process.

\section{THE ROLE OF SPECIES}

A subset of the papers explore interactions among species composition and forest water use and mortality risk (Klockow et al.; Schwarz et al.; van Mantgem et al.). Klockow et al. show that mortality rates and the relationship with stand structure differ across pine species during a recent drought in Texas. Hwang et al. show differences in response between downslope mesophytic trees and upslope xerophytic trees to increasing temperature for a Southern Appalachia site-although they suggest differences may be due to hillslope-scale water subsidy rather than species differences.

How management influences future forests is a function of near-term decision-making that can shape species composition and growth. van Mantgem et al. for example found species differences in drought and thinning responses in their review of tree ring analysis of growth in southwestern US forests.

Changes in precipitation and evaporative demand with climate change and their effects on soil water balances are likely to mediate managed forest drought responses. In a throughfall reduction experiment, Qi et al. showed that deep soil water storage buffered decreases in throughfall inputs. In addition, Hwang et al. showed that downslope water subsidies may decrease with increasing upslope evaporative demand and the vulnerability of downslope mesophytic species to drought. Further, coincident changes in temperature and water availability interact to produce contrasting climate change responses across forests. For example, as shown by Ruiz-Pérez and Vico, increased temperatures increased productivity in water-rich northern Boreal regions, whereas it decreased productivity in already water-limited southern regions.

\section{SUMMARY}

Most of the studies in our collection focus on semi-arid environments, where increases in drought-related forest mortality have been widespread in recent years. As climate changes, however, the concepts and findings presented in this collection will be relevant to geographic regions where drought related forest impacts were once relatively rare. Ruiz-Pérez and Vico offer a boreal forest perspective, and map drought vulnerability in Northern Europe to identify where forest management actions, such as those described by other papers in this collection, are likely to be needed in the future.

Taken together the studies in this Research Topic confirm that forest water use and drought responses are intimately tied to forest structure and composition, but that these relationships are sensitive to local-to-regional-scale variability in climate, species, and geologic/topographic setting. Efforts to mitigate drought vulnerability by active forest management must therefore take this variability into account; i.e., a one-size-fits-all approach is unlikely to be successful. New research that integrates both modeling and monitoring tools that can target specific sites and scales where management actually occurs is needed if we are to successfully use forest management to address increasing forest drought vulnerability in our changing climate.

\section{AUTHOR CONTRIBUTIONS}

All authors contributed to writing of the editorial.

\section{ACKNOWLEDGMENTS}

We thank all of the contributors to this collection and to Julia Schwarz for her help in developing and organizing the theme.

Conflict of Interest: The authors declare that the research was conducted in the absence of any commercial or financial relationships that could be construed as a potential conflict of interest.

Copyright (c) 2021 Tague, Hurteau and Parolari. This is an open-access article distributed under the terms of the Creative Commons Attribution License (CC BY). The use, distribution or reproduction in other forums is permitted, provided the original author(s) and the copyright owner(s) are credited and that the original publication in this journal is cited, in accordance with accepted academic practice. No use, distribution or reproduction is permitted which does not comply with these terms. 